\title{
Application of Ferrite Film Formation Process to BWR Plants
}

\author{
H. HOSOKAWA ${ }^{\text {a) }}$, M. NAGASE ${ }^{\text {b) }}$ and M. FUSE ${ }^{\text {b) }}$
}

a) Hitachi Research Laboratory, Hitachi, Ltd., 7-2-1 Omika-cho, Hitachi-shi, Ibaraki 319-1221, Japan

b) Hitachi Works, Hitachi-GE Nuclear Energy, Ltd., 3-1-1 Saiwai-cho, Hitachi-shi, Ibaraki 317-0073, Japan

\begin{abstract}
The formation process of a ferrite oxide film, which can effectively suppress radioactive nuclide deposition on piping surfaces of BWR reactor water recirculation system, was evaluated from the viewpoints of scale-up from a 1 liter flask scale to a $10 \mathrm{~m}^{3}$ plant scale. To get a thin and closely packed oxide film, the $\mathrm{pH}$ and oxidation-reduction potential values should be maintained within the magnetite stability domain in the Pourbaix diagram of the iron-water system by controlling the hydrazine concentration. The selected film forming conditions were confirmed using the flow system apparatuses of 1/500 and 1/10 actual plant scales. This film formation process could be evaluated taking into consideration the charge balance and chemical equilibrium equations of each reaction involved in the film formation. The method was applied to an actual plant just after the chemical decontamination.
\end{abstract}

Key Words: Ferrite coating, Boiling water reactor, Dose rate reduction

\section{INTRODUCTION}

In boiling water reactors (BWRs) corrosion products that are released from primary structural materials into the coolant are transported to in-core regions. These corrosion products deposit on the boiling region of fuel cladding surfaces, where they are irradiated by neutrons and become radioactive species. These species are redissolved into reactor water and become radioactive ions. Most of the ions redeposit on the fuel cladding surface. However, some of ions reach the surface of the recirculation piping. Thick oxide film incorporating the radioactive species in their structure develop on the components, and so become a radiation source. Since ${ }^{60} \mathrm{Co}$ is the main nuclide of the radiation source, the mechanisms of cobalt accumulation in the oxide layer of steel have been studied by several groups [1-3]. For the last decade, chemical decontamination at the beginning of a periodical inspection has been applied to many Japanese BWR plants in order to reduce radiation exposure. However, following the chemical decontamination, a rapid dose rate increase could be seen in some plants after just a few operation cycles [4]. Oxide film, which easily incorporates radioactivity, might be formed after the chemical decontamination. To develop a suppression method for film formation, incorporation phenomena of ${ }^{60} \mathrm{Co}$ into oxide film formed on stainless steel piping was investigated in simulated BWR conditions. The investigation showed that ferrite plating suppressed ${ }^{60} \mathrm{Co}$ incorporation into the oxide film formed on the stainless steel piping by suppression of base metal corrosion. Basic requirements in the ferrite film coating process for the suppression of the recontamination were identified as follows.

(1) Chemical species included in the ferrite film formation agents cannot accelerate stress corrosion cracking.

(2) The chemical agents for ferrite film formation can be decomposed after the process to minimize radioactive wastes.

(3) The ferrite film can be formed using the chemical decontamination apparatus.

Iron (II) formate $\left(\mathrm{Fe}(\mathrm{HCOO})_{2}\right)$, hydrogen peroxide, and hydrazine were selected as the agents for ferrite film formation that satisfy the above requirements [5]. The ferrite film formation conditions had been optimized in a batch system with a 1 liter flask [6]. On the other hand, the volume of ferrite film formation solution in an actual plant is about $10 \mathrm{~m}^{3}$. It was necessary to evaluate the influence of the scale-up of the ferrite film formation system. In this study, the obtained conditions of ferrite film formation in the flask examination were confirmed with flow system apparatuses of 1/500 and $1 / 10$ actual plant scales. Finally, the results of the application of this method in a BWR plant are discussed.

\section{SCALE-UP EXPERIMENTS}

It is difficult to let the film formation solution flow in the

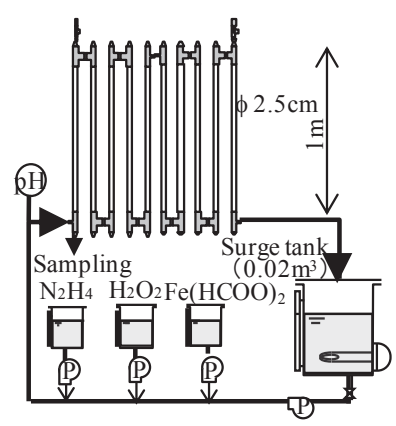

(a) 1/500 scale apparatus

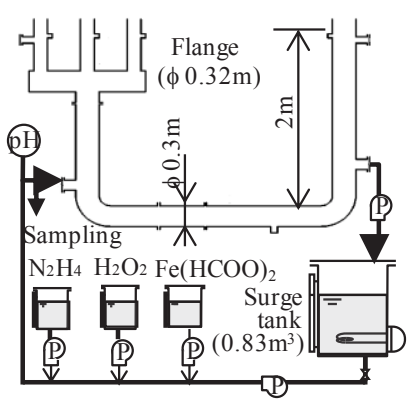

(b) $1 / 10$ scale apparatus

Fig. 1. Schematic diagram of the flow system apparatuses 
piping of a reactor recirculation system for a short time, as in the case of a laboratory experiment with a flask. Therefore flow system apparatuses to simulate the chemical decontamination system of an actual plant were used to confirm the formation of the ferrite film. The apparatus scales were approximately $1 / 500$ and $1 / 10$ of the size of an actual plant. Schematic diagrams of the flow system apparatuses are shown in Fig. 1. Specifications of the experimental apparatuses and the actual plant are shown in Table I. Retention time which meant one circulation time of ferrite film formation solution in each apparatus was approximately the same.

\section{A. 1/500 Scale Flow System Apparatus Experiment}

The $\mathrm{pH}$ dependence of the amount of film formed was observed in the flask experiment. Therefore, the $\mathrm{pH}$ dependence of the amount of film formed in the 1/500 scale flow system apparatus had to be confirmed. Type 316 stainless steel specimens $(8 \mathrm{~mm}$ X $15 \mathrm{~mm}$ X $1.5 \mathrm{~mm})$ were polished with 600-grit emery paper and degreased with acetone. The specimens were then set in a stainless steel pipe $(\phi 2.5 \mathrm{~cm} \mathrm{X} 1 \mathrm{~m})$; nitrogen gas was bubbled through the water in the surge tank to remove dissolved oxygen. Water $(20 \mathrm{~kg}$ ) was poured into the surge tank of the 1/500 scale apparatus, and the water could be heated to $363 \mathrm{~K}$. Iron (II) formate solution was injected into the circulating hot water so that the iron (II) concentration was $5.2 \mathrm{mmol} / \mathrm{kg}$. After the injection of iron (II) formate was finished, hydrogen peroxide solution was injected into the circulating hot water to give a hydrogen peroxide concentration of $0.5 \mathrm{mmol} / \mathrm{kg}$. Finally, hydrazine was injected into the mixed solution to maintain the $\mathrm{pH}$ from 6.3 to 7.4. To compensate for the $\mathrm{pH}$ decrease due to ferrite formation reaction, the injection of hydrazine was continued to maintain the $\mathrm{pH}$ of the mixed solution at the set $\mathrm{pH}$ value. When the flow system apparatus was operating, the ferrite film formation solution was sampled so that the concentrations of iron (II) ion and hydrazine could be measured. After hydrazine had been injected for $4 \mathrm{~h}$, specimens were removed so that the amount of ferrite film formed on them could be measured from their weight gains.

\section{B. 1/10 Scale Flow System Apparatus Experiment}

The relationship between iron (II) concentration and hydrazine concentration was investigated for the two scale apparatuses under the selected $\mathrm{pH}$ condition from the $1 / 500$ scale experiment which was $\mathrm{pH}=7$. The procedure was similar to that of the $1 / 500$ scale experiment. Differences were the volume of poured water, and that a part of the circulation system piping was open to air. $830 \mathrm{~kg}$ of water was poured into the surge tank of the 1/10 scale apparatus. Unlike the flask and 1/500 scale apparatus experiments, the circulating solution in the 1/10 scale apparatus came in contact with air just as it would in an actual plant, and oxygen in the air promoted oxidation of iron (II) ion in the ferrite film formation solution. To compensate for the $\mathrm{pH}$ decrease due to hydrolysis following the oxidation reaction and ferrite formation reaction, the injection of hydrazine was continued to maintain the $\mathrm{pH}$ of the mixed solution at 7 . When the flow system apparatus was operating, the ferrite film formation solution was sampled so that the concentrations of iron (II) ion and hydrazine could be measured.

\section{RESULTS AND DISCUSSION}

\section{A. pH Dependence of the Amount of Film Formed in Flow System Apparatuses}

The $\mathrm{pH}$ dependence of the amount of film formed in the 1/500 scale apparatus and the $1 \mathrm{~L}$ flask is shown in Fig. 2 . The $\mathrm{pH}$ dependence of the two experiments were similar. A magnetite film was hardly formed below $\mathrm{pH} 6.5$ in both experiments. The amount of film formed in the $\mathrm{pH}$ region higher than 6.8 was sufficient for suppression of recontamination and had no decreasing tendency. However addition of more than the required amount of hydrazine is not desirable because unnecessary hydrazine addition increases the load for reagent decomposition. Therefore, $\mathrm{pH} 7 \mathrm{was}$ selected to form ferrite film for the $1 / 10$ scale apparatus experiment.

\section{B. Chemical Equilibrium in Ferrite Film Formation Solution}

The relationship between iron (II) ion concentration and hydrazine concentration in the ferrite film formation solution in 1/500 and 1/10 scale apparatuses is shown in Fig. 3. The relationship between iron (II) ion concentration and hydrazine concentration in both experiments was very similar. To describe the relationship between the iron (II) ion concentration, 
formic acid concentration, hydrazine concentration, and $\mathrm{pH}$, the reactions of chemicals in the ferrite film formation solution and the corresponding equilibrium constants were taken into consideration [6]. The hydrolysis reaction equation of the iron (II) ions, the dissociation reaction of formic acid, the dissociation reaction of hydrazine,
Table II Equilibrium equations and constants in ferrite film formation solution.

\begin{tabular}{|c|c|c|}
\hline Equilibrium Equations & Equilibrium constants (at $373 \mathrm{~K}$ ) & Eq. No \\
\hline $\mathrm{Fe}^{2+}+\mathrm{H}_{2} \mathrm{O}=\mathrm{Fe}(\mathrm{OH})^{+}+\mathrm{H}^{+}$ & $K_{\mathrm{Fe} 1}=\left[\mathrm{Fe}(\mathrm{OH})^{+}\right]\left[\mathrm{H}^{+}\right] /\left[\mathrm{Fe}^{2+}\right]=3.98 \times 10^{-8}$ & (1) \\
\hline $\mathrm{Fe}^{2+}+2 \mathrm{H}_{2} \mathrm{O}=\mathrm{Fe}(\mathrm{OH})_{2}+2 \mathrm{H}^{+}$ & $K_{\mathrm{Fe} 2}=\left[\mathrm{Fe}(\mathrm{OH})_{2}\right]\left[\mathrm{H}^{+}\right]^{2} /\left[\mathrm{Fe}^{2+}\right]=3.98 \times 10^{-17}$ & (2) \\
\hline $\mathrm{Fe}^{2+}+3 \mathrm{H}_{2} \mathrm{O}=\mathrm{Fe}(\mathrm{OH})_{3}^{-}+3 \mathrm{H}^{+}$ & $K_{\mathrm{Fe} 3}=\left[\mathrm{Fe}(\mathrm{OH})_{3}^{-}\right]\left[\mathrm{H}^{+}\right]^{3} /\left[\mathrm{Fe}^{2+}\right]=2.51 \times 10^{-25}$ & (3) \\
\hline $\mathrm{HCOOH}=\mathrm{HCOO}^{-}+\mathrm{H}^{+}$ & $K_{a F}=\left[\mathrm{HCOO}^{-}\right]\left[\mathrm{H}^{+}\right] /[\mathrm{HCOOH}]=1.12 \times 10^{-4}$ & (4) \\
\hline $\mathrm{N}_{2} \mathrm{H}_{5}^{+}=\mathrm{N}_{2} \mathrm{H}_{4}+\mathrm{H}^{+}$ & $K_{a H}=\left[N_{2} H_{4}\right]\left[H^{+}\right] /\left[N_{2} H_{5}^{+}\right]=1.07 \times 10^{-7}$ & (5) \\
\hline $\mathrm{H}_{2} \mathrm{O}=\mathrm{H}^{+}+\mathrm{OH}^{-}$ & $K_{W}=\left[H^{+}\right]\left[O H^{-}\right]=5.3 \times 10^{-13}$ & (6) \\
\hline
\end{tabular}
and all equilibrium constant equations are listed in Table II. Because the solubility of iron (III) ions is very low around the target $\mathrm{pH}$ of near neutrality, ionic species related to iron (III) ions are neglected. The charge balance equation in the case of the ferrite film formation solution is given as

$$
\left[\mathrm{H}^{+}\right]+2\left[\mathrm{Fe}^{2+}\right]+\left[\mathrm{Fe}(\mathrm{OH})^{+}\right]-\left[\mathrm{Fe}(\mathrm{OH})_{3}^{-}\right]-\left[\mathrm{OH}^{-}\right]+\left[\mathrm{N}_{2} \mathrm{H}_{5}^{+}\right]-\left[\mathrm{HCOO}^{-}\right]=0 .
$$

Substituting Eqs. (1) and (3) to (6) into Eq. (7) gives the following equation.

$$
\begin{aligned}
& {\left[H^{+}\right]+\left(2+\frac{K_{F e 1}}{\left[H^{+}\right]}-\frac{K_{F e 3}}{\left[H^{+}\right]^{3}}\right)\left[F e^{2+}\right]-\frac{K_{w}}{\left[H^{+}\right]}+\frac{\left[H^{+}\right]\left[N_{2} H_{4}\right]_{T}}{\left[H^{+}\right]+K_{a H}}-\frac{K_{a F}[\mathrm{HCOOH}]_{T}}{\left[H^{+}\right]+K_{a F}}=0} \\
& {\left[\mathrm{~N}_{2} \mathrm{H}_{4}\right]_{\mathrm{T}} \text { : Total hydrazine concentration : }\left[\mathrm{N}_{2} \mathrm{H}_{4}\right]_{\mathrm{T}}=\left[\mathrm{N}_{2} \mathrm{H}_{4}\right]+\left[\mathrm{N}_{2} \mathrm{H}_{5}^{+}\right]} \\
& {[\mathrm{HCOOH}]_{\mathrm{T}} \text { : Total formic acid concentration : }[\mathrm{HCOOH}]_{\mathrm{T}}=[\mathrm{HCOOH}]+\left[\mathrm{HCOO}^{-}\right]}
\end{aligned}
$$

The injection rates of hydrazine were controlled so that the $\mathrm{pH}$ conditions of the film formation solutions could be maintained 7 for these experiments. The relationship between $\left[\mathrm{Fe}^{2+}\right]$ and $\left[\mathrm{N}_{2} \mathrm{H}_{4}\right]_{\mathrm{T}}$ in Eq. (8) at pH 7 is shown in Fig. 3 as experimental results. Changes of the concentrations of iron (II) ions and hydrazine in the ferrite film formation solution were in accord with Eq. (8). The confirmed ferrite film formation procedure that was maintained the $\mathrm{pH}$ value at $7 \mathrm{was}$ applied to the actual plant. Changes of the concentrations of iron and hydrazine in the ferrite film formation solution in the actual plant are shown in Fig. 3. These concentration changes in the ferrite film formation solution in the actual plant were the same as predicted by Eq. (8) and the experimental results that were obtained for the flow system apparatuses. It was confirmed that a ferrite film quantity of $3 \mathrm{~g} / \mathrm{m}^{2}$ was formed on the specimens in the actual plant system [7].

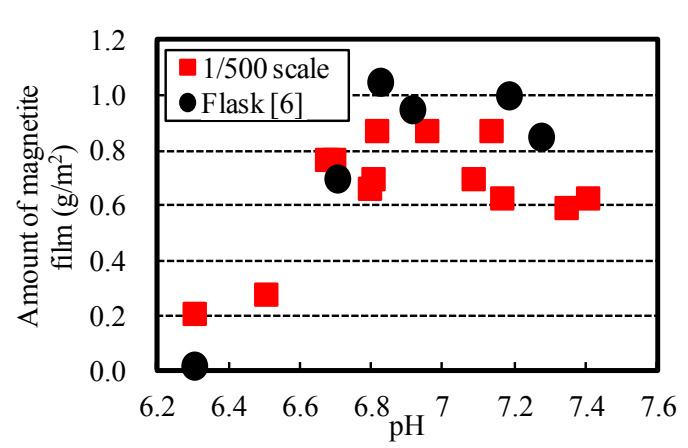

Fig. 2. pH dependence of amount of ferrite film formation

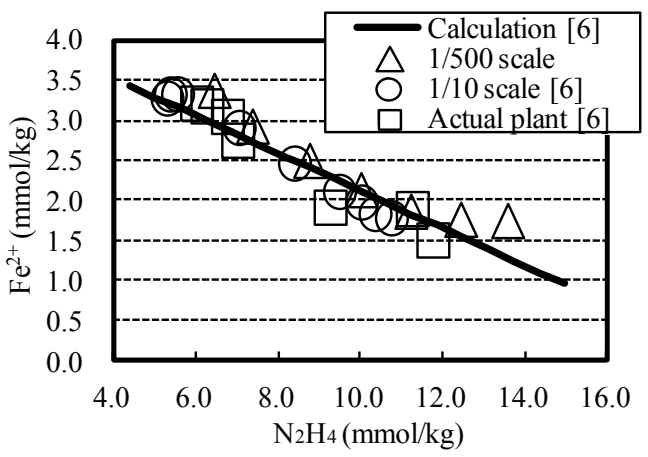

Fig. 3. Relationship between iron (II) ion concentration and hydrazine concentration in ferrite film formation solution in the recirculation system

\section{CONCLUSION}

An equation describing the relationship between iron concentration, formic acid concentration, and hydrazine concentration in the ferrite film formation solution was derived from charge balance and chemical equilibrium equations. Changes of the concentrations of the iron (II) ions and hydrazine in the flow systems were verified to be in accord with the equation results. 


\section{REFERENCES}

[1] D. H. Lister, Nucl. Sci. Eng. 58, 239 (1975).

[2] S. Uchida, M. Kitamura, Y. Matsushima, K. Yonezawa, K. Ohsumi and M. Miki, Nucl. Sci. Eng. 77, 496 (1981).

[3] N. Usui, M. Fuse, H. Hosokawa and S. Uchida, J. Nucl. Sci. Tecnol. 42, 75 (2005).

[4] A. Miyazawa, T. Shibano, T. Sato, M. Shimura and K. Iida, Symposium on Water Chemistry and Corrosion of Nuclear Power Plants in Asia, Gyeongju, Korea, 2005, p. 38.

[5] H. Hosokawa, M. Nagase and M. Fuse, J. Nucl. Sci. Technol., 47, 531 (2010).

[6] H. Hosokawa, M. Nagase, M. Fuse and Y. Watanabe, Nucl. Sci. Engineering, in press (2013).

[7] M. Nagase, N. Usui, S. Ouchi, H. Hosokawa, H. Kajitani, A. Yamashita and T. Minmi, 2009 Information System on Occupational Exposure Asia Symposium, Aomori, Japan, 2009, p.8. 